\title{
Introducing the next evolution of the small-caliber-tip transparent hood: enhancing the pocket-creation method by building on previous successes
}

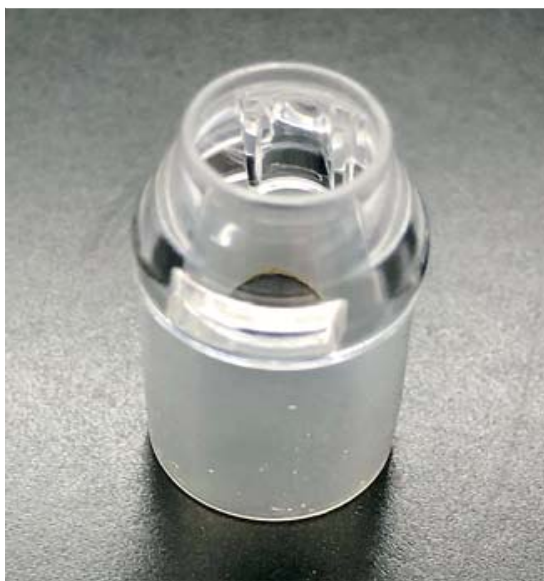

- Fig. 1 The latest small-caliber-tip transparent hood (DH-33GR) with small-diameter opening, short conical protrusion, double drainage slits, redesigned guiderail, and easy-to-attach silicon cylindrical base.

The pocket-creation method facilitates the procedure of endoscopic submucosal dissection (ESD) and results in highquality resected specimens with thick and minimally burned submucosa [14]. The small-caliber-tip transparent hood (ST hood; Fujifilm, Tokyo, Japan) is an essential component of the pocketcreation method, with a conical shape that allows the endoscope tip to enter into the submucosal space quickly and easily [5]. The small-caliber-tip transparent hood provides both traction and countertraction, stretching the submucosa and allowing it to be easily cut with minimal thermal damage. The previous conventional (DH-15GR; Fujifilm) and short small-caliber-tip transparent hoods (DH-28GR; Fujifilm) each had their own advantages and disadvantages. However, the latest hood of this type (DH-33GR; Fujifilm), launched in Japan in June 2019, incorporates the best qualities of both ( $>$ Fig. 1, > Table 1). Features of this latest hood include: 1 ) a small, 7-mm diameter orifice; 2 ) an inner guiderail directing the tips of inserted devices to the center

\begin{tabular}{|l|l|l|l|}
\hline \multicolumn{1}{|c|}{ Table 1 Dimensions of the small-caliber-tip transparent hoods. } \\
\hline & $\begin{array}{l}\text { Latest model } \\
\text { (DH-33GR) }\end{array}$ & $\begin{array}{l}\text { Short model } \\
\text { (DH-28GR) }\end{array}$ & $\begin{array}{l}\text { Conventional model } \\
\text { (DH-15GR) }\end{array}$ \\
\hline Base outer diameter, $\mathrm{mm}$ & 11.8 & 11.8 & 12.2 \\
\hline Tip opening diameter, $\mathrm{mm}$ & 7.0 & 8.0 & 7.0 \\
\hline Protrusion length, $\mathrm{mm}$ & 7.0 & 7.0 & 8.3 \\
\hline
\end{tabular}

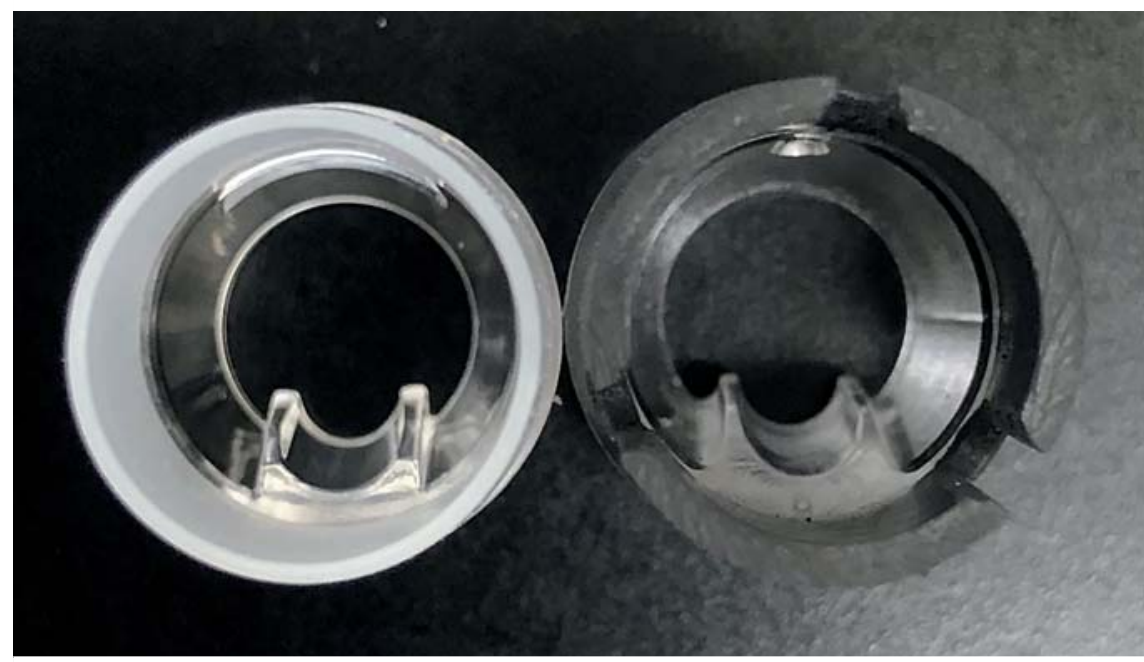

- Fig. 2 Comparison of proximal guiderail edges between the latest small-caliber-tip transparent hood (left, DH-33GR) and the conventional hood (right, DH-15GR). With the previous conventional hood, inserted instruments could become trapped if 1 ) they did not emerge perfectly straight from the working channel, or 2) the guiderail did not align with the working channel of the endoscope. In the latest design, the proximal guiderail edge is wider, solving these issues.

of the endoscopic view (similar to the conventional model); 3) a shorter, 7-mm conical protrusion; 4) double slits facilitating drainage of internal fluid; 5) an easy-to-attach silicon cylindrical base (similar to the short small-caliber-tip transparent hood); and 6) a redesigned proximal guiderail (\$ Fig. 2).

A 40-mm, Paris Ila, laterally spreading lesion in the distal rectum was removed using the pocket-creation method with the latest small-caliber-tip transparent hood ( $>$ Fig. 3, \Video 1). Like the conventional model, the newest hood easily enters into the submucosa. The 7-mm length of the conical protrusion creates closer views in front of the hood. The redesigned guiderail edge facilitates the smooth insertion of hemostatic forceps, with little resistance. The lesion was removed without any adverse events. Pathology revealed a high-grade adenoma with negative vertical and lateral margins.

In conclusion, the newest small-calibertip transparent hood possesses the best qualities of both previous hoods and enhances the performance of the pocketcreation method.

Endoscopy_UCTN_Code_TTT_1AQ_2AD 

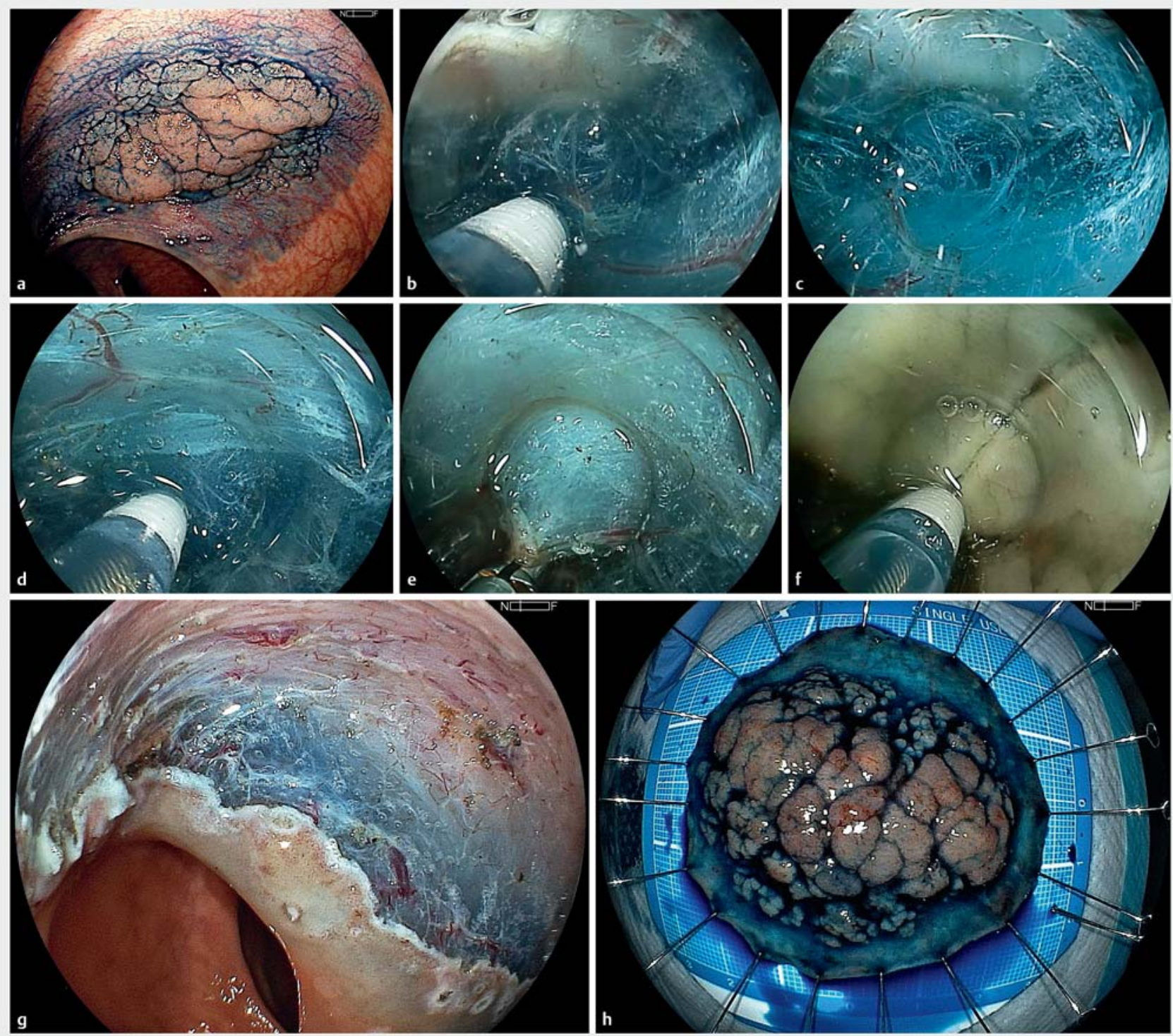

Fig. 3 a 40-mm, Paris Ila, granular, JNET 2A, Kudo's type IV pit pattern, laterally spreading lesion in the distal rectum, sprayed with indigo carmine. $\mathbf{b}$ The newest model of the transparent small-caliber-tip transparent hood easily enters the submucosa after initial mucosal incision (similarly to the conventional hood). $\mathbf{c}$ When the transparent walls of the hood touch the surrounding tissue, light refraction disappears, providing a wide, clear field of view. The short conical protrusion provides closer views of tissue at the front of the hood, magnifying its appearance at the orifice. The submucosa can be examined at a close distance, making it easier to distinguish submucosa from muscularis propria and to identify blood vessels. $\mathbf{d}$ The guiderail guides the knife tip to the center of the endoscopic view, eliminating the need to rotate the endoscope to the 6 o'clock/working channel position. e Unlike the conventional small-caliber-tip transparent hood, the redesigned guiderail, with a larger proximal edge, allows easier insertion of hemostatic forceps without getting stuck at the edge. $\mathbf{f}$ The submucosal pocket is opened after dissection of the entire underlying submucosa of the lesion. $g$ The defect post-endoscopic submucosal dissection with only minimal burning of the submucosa covering the surface of the muscularis propria. h Resected specimen sprayed with indigo carmine. Pathology revealed a high-grade adenoma with negative vertical and lateral margins. 


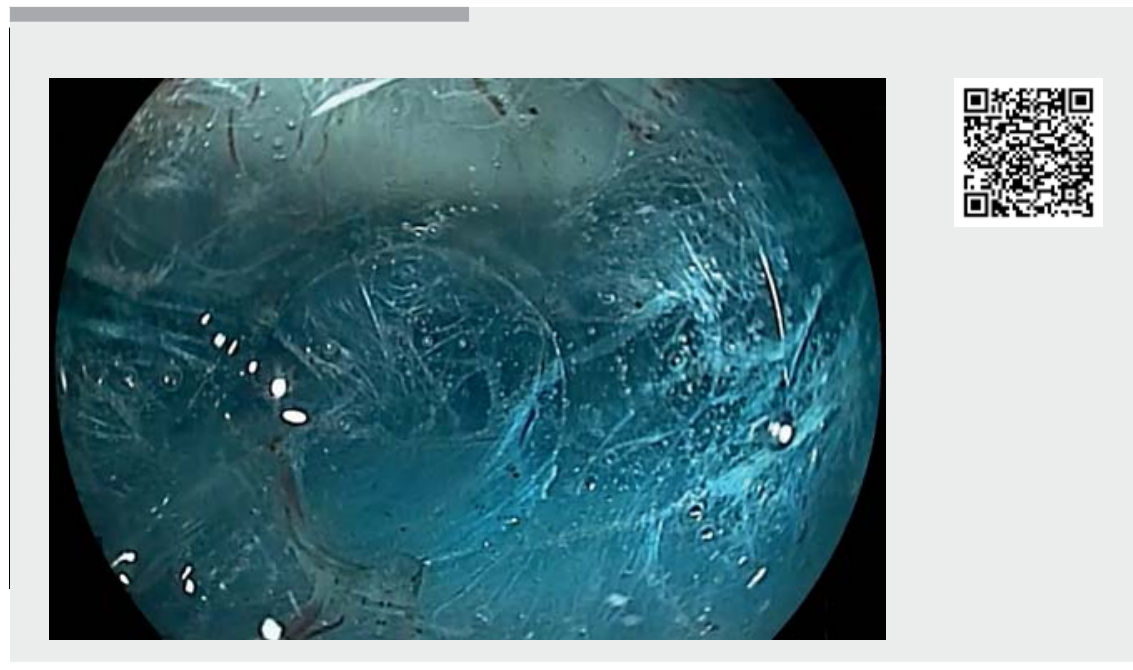

Video 1 Demonstration of pocket-creation method using the small-caliber-tip transparent hood.

[3] Sakamoto H, Hayashi Y, Miura Y et al. Pocket-creation method facilitates endoscopic submucosal dissection of colorectal laterally spreading tumors, non-granular type. Endosc Int Open 2017; 5: E123-E129

[4] Takezawa T, Hayashi Y, Shinozaki S et al. The pocket-creation method facilitates colonic endoscopic submucosal dissection (with video). Gastrointest Endosc 2019; 89: 1045-1053

[5] Yamamoto H, Kawata H, Sunada K et al. Successful en-bloc resection of large superficial tumors in the stomach and colon using sodium hyaluronate and small-caliber-tip transparent hood. Endoscopy 2003; 35: 690-694

\section{Bibliography}

DOI https://doi.org/10.1055/a-1093-0621

Published online: 17.2.2020

Endoscopy 2020; 52: E297-E299

(c) Georg Thieme Verlag KG

Stuttgart - New York

ISSN 0013-726X

\section{Competing interests}

H.Y. has a consultant relationship with Fujifilm Corporation and has received honoraria, grants, and royalties from the company.

\section{The authors}

Yoshikazu Hayashi' ${ }^{1}$, Tatsuma Nomura' ${ }^{1}$, Ralph F. Lee ${ }^{1,2}$, Yoshimasa Miura ${ }^{1}$, Satoshi Shinozaki ${ }^{1,3}$, Keijiro Sunada ${ }^{1}$, Hironori Yamamoto ${ }^{1}$

1 Department of Medicine, Division of Gastroenterology, Jichi Medical University, Shimotsuke, Japan

2 Department of Medicine, Division of Gastroenterology, University of Ottawa, Ottawa, Ontario, Canada

3 Shinozaki Medical Clinic, Utsunomiya, Japan

\section{Corresponding author}

\section{Hironori Yamamoto, MD}

Department of Medicine, Division of Gastroenterology, Jichi Medical University, Shimotsuke, Japan, 3311-1 Yakushiji, Shimotsuke, Tochigi, 329-0498, Japan Fax: +81-285-40-6598 ireef@jichi.ac.jp

\section{References}

[1] Hayashi Y, Sunada K, Takahashi $\mathrm{H}$ et al. Pocket-creation method of endoscopic submucosal dissection to achieve en bloc resection of giant colorectal subpedunculated neoplastic lesions. Endoscopy 2014; 46 (Suppl. 01): E421-E422

[2] Hayashi Y, Miura Y, Yamamoto H. Pocketcreation method for the safe, reliable, and efficient endoscopic submucosal dissection of colorectal lateral spreading tumors. Dig Endosc 2015; 27: 534-535. doi:10.1111/ den. 12465 